\title{
VURD syndrome in an infant presenting with potentially fatal staphylococcal urinary tract infection and septicaemia
}

\author{
Carla Ferreira, ${ }^{1}$ Marlene Rodrigues, ${ }^{2}$ Armando Reis, ${ }^{3}$ Teresa Costa ${ }^{3}$
}

${ }^{1}$ Centro Hospitalar do Alto Ave EPE, Guimaraes, Portugal ${ }^{2}$ Hospital de Braga, Braga, Braga, Portugal

${ }^{3}$ Centro Materno Infantil Do Norte, Centro Hospitalar do Porto, Porto, Portugal

Correspondence to Dr Marlene Rodrigues, rodrigues.f.marlene@gmail.com

Accepted 12 November 2016

CrossMark

To cite: Ferreira $C$ Rodrigues $\mathrm{M}$, Reis $\mathrm{A}$, et al. BMJ Case Rep Published online: [please include Day Month Year] doi:10.1136/ bcr-2016-218168

\section{DESCRIPTION}

A newborn (NB) boy was delivered at 39 weeks of gestation with $4160 \mathrm{~g}$ weight and an APGAR score of $8 / 9$. The pregnancy was uneventful, with normal first and second trimester ultrasound. The third trimester ultrasound revealed an isolated right kidney hydronephrosis, a normal sized bladder without thickening of wall as well a normal amniotic fluid volume. Kidney and bladder ultrasound (KBU) scan performed 48 hours after birth showed persistence of right kidney hydronephrosis as well dilation of right ureter. The left kidney and ureter were normal and alteration in bladder volume, bladder wall thickness and posterior urethra were observed. Trimethoprim prophylaxis was started, and the NB was discharged home in good condition. At 1 month age he was revaluated and remained asymptomatic, with an appropriate weight gain. The parents reported normal micturition with good urinary stream, without straining or dribbling. No changes were found on physical examination and the bladder was not palpable. In the second month of life the infant was admitted to the emergency department with fever and urinalysis, collected by urinary stream revealed pyuria. A diagnosis of urinary tract infection (UTI) was suspected and treatment with cefuroxime was initiated. A Staphylococcus haemolyticus sensitive only to vancomycin was isolated in urine and blood cultures, and treatment with vancomycin was initiated. A KBU scan performed revealed persistence of isolated right-sided kidney and ureteral dilation. Fever persisted intermittently during 2 weeks. A voiding cystourethrogram (VC) was performed which showed a right-sided grade $\mathrm{V}$ vesicoureteral reflux, a dilation and elongation of the posterior urethra and a linear radiolucent band in distal posterior urethra (figure 1), which confirmed the diagnosis of posterior urethral valves (PUV). Urethrocystoscopy confirmed the presence of PUV and the valves were resected. The infant was discharged home in good condition and no more febrile UTIs were observed.

PUVs occur in 1 in 5000 to 1 in 8000 live births $^{1}$ and nowadays the diagnosis is frequently suspected in utero with prenatal ultrasound scan showing oligohydramnios, bilateral hydronephrosis, distended bladder and a thickened bladder wall. ${ }^{2}$
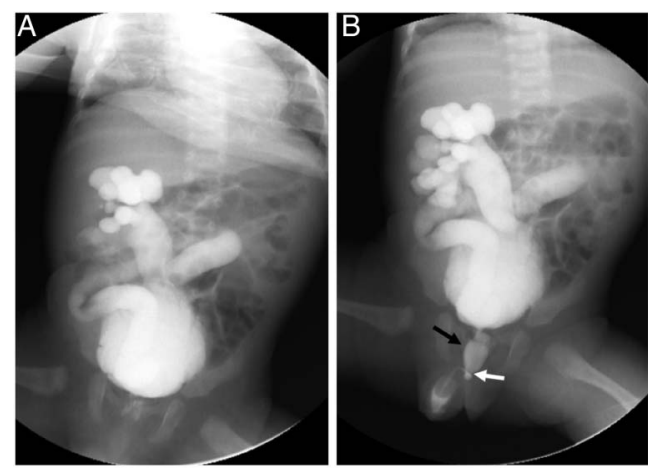

Figure 1 Voiding cystourethrogram (VC). After filling cystourethrogram a right-sided grade $V$ vesicoureteral reflux was observed (panel A) and VC showed dilation and elongation of the posterior urethra and a linear radiolucent band in distal posterior urethra consistent with the diagnosis of posterior urethral valves (panel B).

Frequently PUV newborns may present with unilateral vesicoureteral reflux. VURD (posterior urethral Valve, Unilateral vesicoureteral reflux, Renal Dysplasia) syndrome was identified by Hovver and Duckett in 1982 with the unique relationship between valves, reflux and dysplasia. They noted preserved contralateral renal function into a non-refluxing kidney and proposed that the mechanism of this protection lies in the fact that the refluxing collecting system acts as a pressure pop-off. ${ }^{3}$ However, the protective effects of VURD in the long-term has not been as helpful as originally expected. Cuckow et $a l^{4}$ concluded that renal function deteriorated in patients with VURD syndrome in their cohort of patients on long-term follow-up. About half of the patients with VURD syndrome had renal scarring in the contralateral kidney in the series reported by Narasimhan et al. ${ }^{5}$ Independently of presentation the diagnosis of PUV is confirmed by the typical findings of VC. Most common organism in UTI is Escherichia coli, however, unusual organisms including Staphylococcus are encountered in neonates and infants. Primary neonatal methicillinresistant Staphylococcus aureus pyonephrosis has been reported even in a urinary system with unilateral refluxing dilated upper tracts. ${ }^{6}$ 


\section{Learning points}

- Bilateral hydronephrosis and distended bladder with thickened wall are classical findings in posterior urethral valves (PUV) cases. Less frequently PUV in the new born/ infant may present with unilateral vesicoureteral reflux. This 'pop off mechanism' permits the high pressure bladder to focus in refluxing kidney, sparing and protecting the non-refluxing kidney.

- Voiding cystourethrogram (VC) is the gold standard in PUV diagnosis, and shows pathognomonic findings: dilation and elongation of the posterior urethra and a linear radiolucent band distal to posterior urethra which indicates PUV.

- VURD (posterior urethral Valve, Unilateral vesicoureteral reflux, Renal Dysplasia) syndrome should be considered as possible differential diagnosis when late prenatal or neonatal scan shows unilateral hydroureteronephrosis. A dilated posterior urethra with 'keyhole sign' should be looked for with early VC to be arranged in order to complete the VURD association.
Contributors CF was involved in planning, conduct, conception and design, data collection, manuscript writing, analysis and interpretation of data. MR took part in conception and design, data collection, manuscript writing, analysis and interpretation of data. AR was involved in conception and design, critical review of the content of the manuscript, analysis and interpretation of data. TC took part in conception and design, critical review of the content of the manuscript, analysis and interpretation of data. All authors contributed in the clinical orientation of the patient whose clinical case is reported, as well as to article preparation.

Competing interests None declared.

Provenance and peer review Not commissioned; externally peer reviewed.

\section{REFERENCES}

1 Thakkar D, Deshpande AV, Kennedy SE. Epidemiology and demography of recently diagnosed cases of posterior urethral valves. Pediatr Res 2014;76:560-3.

2 Brown T, Mandell J, Lebowitz RL. Neonatal hydronephrosis in the era of sonography. AJR Am J Roentgenol 1987;148:959.

3 Hoover DL, Duckett JW Jr. Posterior urethral valves, unilateral reflux and renal dysplasia: a syndrome. J Urol 1982;128:994-7.

4 Cuckow PM, Dinneen MD, Risdon RA, et al. Long-term renal function in the posterior urethral valves, unilateral reflux and renal dysplasia syndrome. J Urol 1997; 158:1004-7.

5 Narasimhan KL, Mahajan JK, Kaur B, et al. The vesicoureteral reflux dysplasia syndrome in patients with posterior urethral valves. J Urol 2005;174:1433-5.

6 Patel R, Nwokoma N, Ninan GK. Primary neonatal MRSA pyonephrosis. Int Urol Nephrol 2013;45:939-42.

Copyright 2016 BMJ Publishing Group. All rights reserved. For permission to reuse any of this content visit http://group.bmj.com/group/rights-licensing/permissions.

BMJ Case Report Fellows may re-use this article for personal use and teaching without any further permission.

Become a Fellow of BMJ Case Reports today and you can:

- Submit as many cases as you like

- Enjoy fast sympathetic peer review and rapid publication of accepted articles

- Access all the published articles

- Re-use any of the published material for personal use and teaching without further permission

For information on Institutional Fellowships contact consortiasales@bmjgroup.com

Visit casereports.bmj.com for more articles like this and to become a Fellow 